\title{
Kienböck's Disease: Diagnosis and the Different Ways of Management
}

\author{
Elalfy M Mohamed ${ }^{1 *}$ and Nour A Khaled ${ }^{2}$ \\ ${ }^{1}$ Orthopaedic surgery resident at Mansoura University Hospital, Faculty of medicine, Egypt \\ ${ }^{2}$ Orthopedic surgery lecturer at Mansoura University Hospital, Faculty of medicine, Egypt
}

Submission: October 27, 2017; Published: November 13, 2017

Corresponding author's: Elalfy M Mohamed, Faculty of Medicine, Orthopaedic surgery resident at Mansoura University Hospitals, Egypt, Email: elalfy2299@gmail.com

Nour A Khaled, Faculty of medicine, Orthopedic surgery lecturer at Mansoura University Hospital, Egypt.

Abbreviations: MRI: Magnetic Resonance Imaging; STT: Scapho Trapezio Trapezoid; SC: Scapho Capitate (SC); PRC: Proximal Row Carpectomy;

CH: Capito Hamate

\section{Background}

Kienböck's disease is a condition of uncertain etiology that results in osteonecrosis of the carpal lunate. It usually affects the dominant wrist of men aged 20-40 years [1,2] (Figure 1).

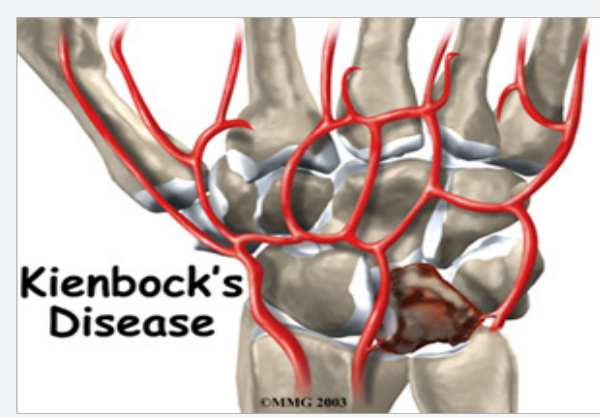

Figure 1: Kienböck's disease is a condition of uncertain etiology that results in osteonecrosis of the carpal lunate. It usually affects the dominant wrist of men aged 20-40 years.

\section{Etiology}

The etiology of Kienböck's disease is not clear. Most likely, it occurs as a result of repeated loads to a "lunate at risk" by virtue of its unique vascular or mechanical environment. Although the underlying etiology of this condition is not known, the final results of fragmentation and collapse are secondary to osteonecrosis.

\section{Pathophysiology}

Thought to be caused by multiple factors:

i. Biomechanical factors,

ii. Ulnar negative variance (leads to increased radiallunate contact stress)[3], iii. Decreased radial inclination,

iv. Repetitive trauma [4],

v. Anatomic factors,

vi. Geometry of lunate,

vii. Vascular supply to lunate (patterns of arterial blood supply have differential incidences of AVN or disruption of venous outflow leading to increased intraosseous pressure) $[5,6]$.

\section{Pathology}

The pathologic changes are equivalent to those of avascular necrosis of other bones. There is disruption of critical blood supply leading to bone infarction, central necrosis and surrounding hyperaemia. Microfractures ensue resulting in flattening and deformity of the bone surface. In $70 \%$ of lunates there is vascular supply multiple vessels either volarly or dorsally. In the remaining $30 \%$ only a single vessel is present volarly and dorsally, which may explain some of the vulnerability of the lunate to avascular necrosis.

\section{Clinical Manifestations}

a. Wrist pain that radiates up the forearm and stiffness, tenderness, and swelling over lunate.

b. Passive dorsiflexion of middle finger produces characteristic pain.

c. Limitation of wrist motion, usually dorsiflexion. 


\section{Orthopedics and Rheumatology Open Access Journal}

d. Weakness of grip.

e. Pain and weakness increase as the lunate collapses and degenerative changes develop, making the disability both severe and chronic [2].

\section{Radiological Findings}

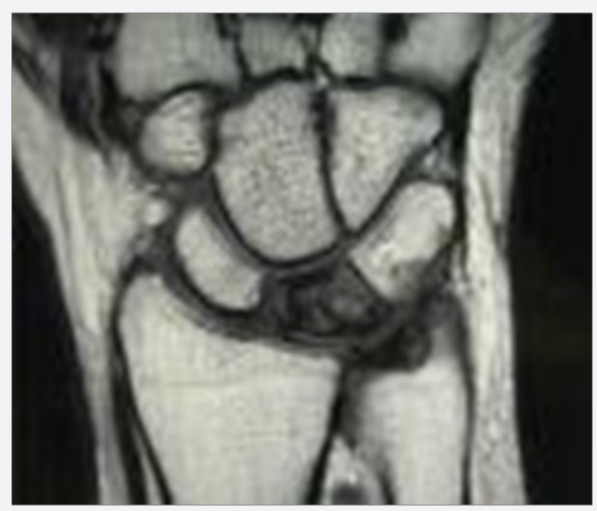

Figure 2: The most reliable test to assess the blood supply of the lunate is Magnetic Resonance Imaging (MRI), CT scanning, specialized CT scanning and bone scan may also be used.
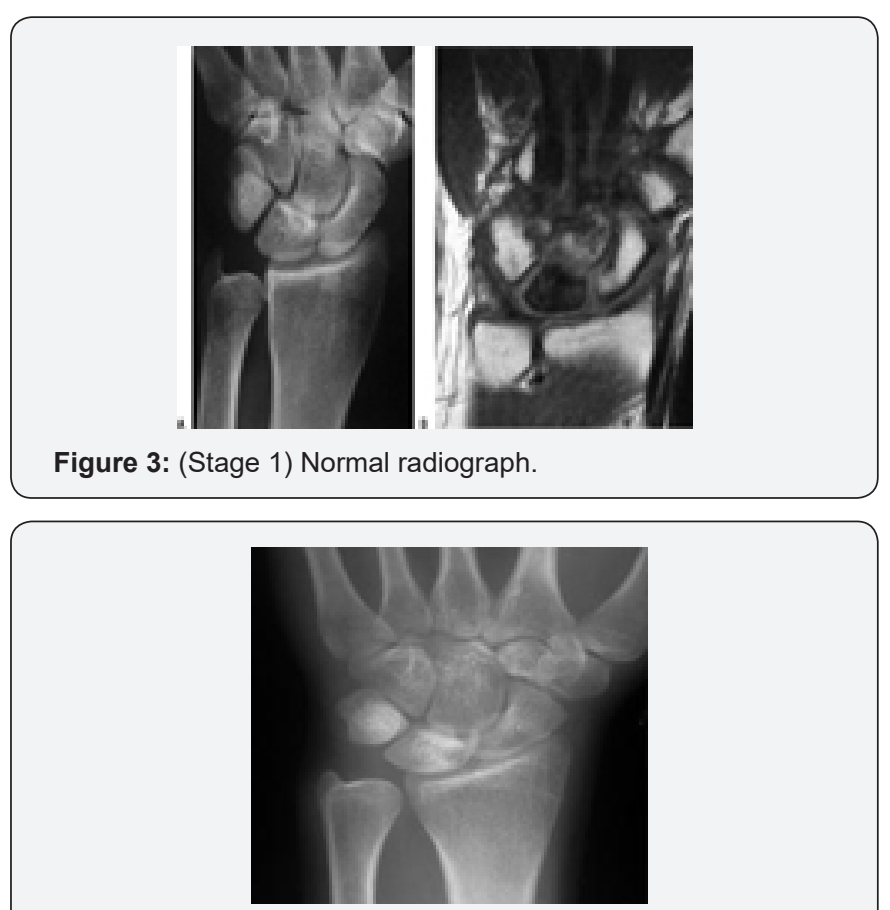

Figure 4: (Stage 2) Increased radio density of the lunate with possible decrease of lunate height on the radial side only.

In early stages of this disease, the x-rays may be normal and other tests are needed to confirm the diagnosis. Most likely, the most reliable test to assess the blood supply of the lunate is Magnetic Resonance Imaging (MRI), CT scanning, specialized CT scanning and bone scan may also be used (Figure 2). The Stahl classification of Kienböck's disease, modified by Lichtman, is the most commonly used staging system and is useful in the treatment of Kienböck's disease (avascular necrosis of the lunate) [7]. This system divides the disease into four stages (Figures 3-6):
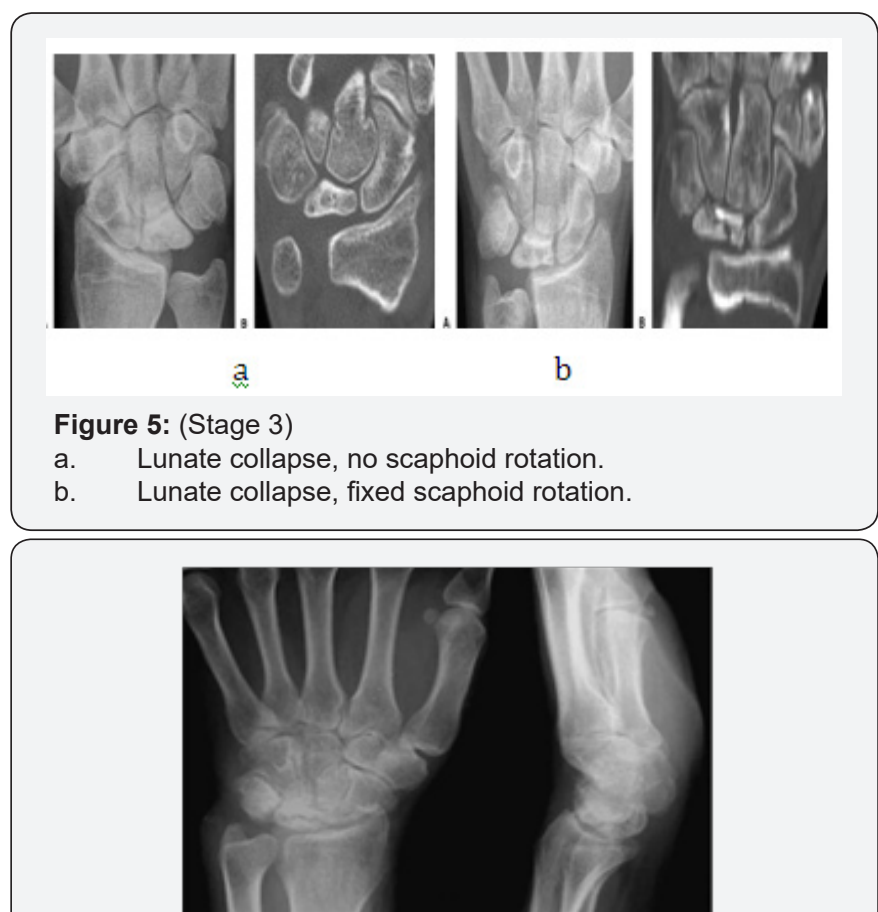

Figure 6: (Stage 4) Degenerative changes around lunate.

i. Stage I: normal radiograph.

ii. Stage II: increased radiodensity of the lunate with possible decrease of lunate height on the radial side only.

iii. Stage III:

a. Lunate collapse, no scaphoid rotation.

b. Lunate collapse, fixed scaphoid rotation.

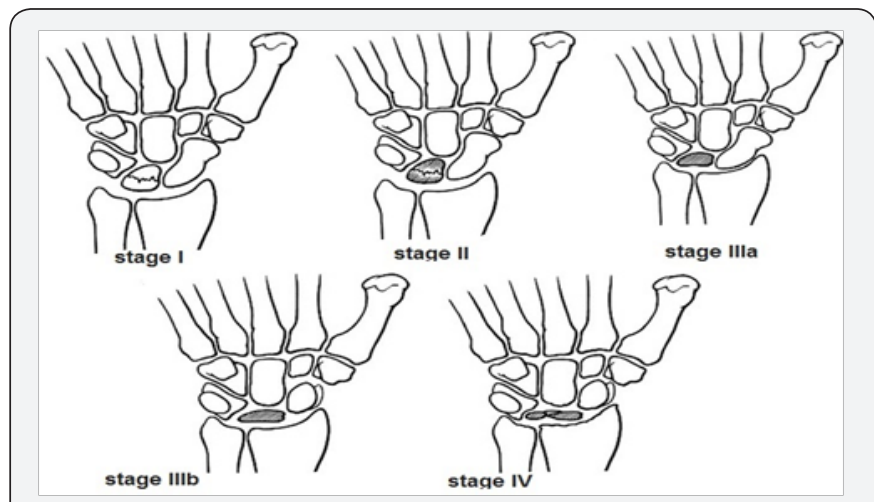

Figure 7: The Stahl classification of Kienböck's disease.

iv. Stage IV: degenerative changes around lunate (Figure 7).

\section{Arthroscopic Classification [8,9]}

Bain and Begg first described their arthroscopic classification in 2006 .This is based on the number of nonfunctional articular surfaces. 
a. Grade 0: All articular surfaces are functional.

b. Grade 1: One nonfunctional articular surface, usually the proximal articular surface of the lunate.

c. Grade 2: Two nonfunctional articular surfaces. Divided into types $\mathrm{A}$ and $\mathrm{B}$.

Grade 2A: The proximal lunate and the lunate facet of the radius.

Grade 2B: Proximal articular surface of the lunate, and distal articular surface of the lunate.

d. Grade 3: Three nonfunctional articular surfaces (the lunate facet of the radius, proximal and distal articular surfaces of the lunate), with a preserved head of capitate.

e. Grade 4: All four articular surfaces are nonfunctional (Figure 8).

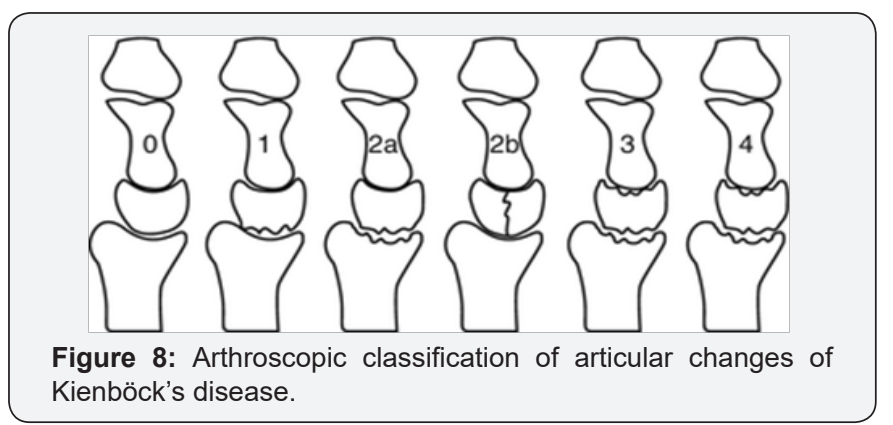

The authors have noted the following observations:

a. The degree of synovitis correlates with the degree of articular damage.

b. The severity of articular changes is underestimated by plain radiographs.

c. Findings at arthroscopy commonly change the initial treatment plan.

d. In certain cases the articular cartilage envelope remains intact with collapse of the subchondral bone plate. This is an important subgroup where the lunate has probably revascularized. In these patients, particularly if they are young, conservative treatment may be considered, as there is potential to heal and stabilize [9].

\section{Management}

\section{Nonoperative}

Observation, immobilization and NSAIDS.

Certainly, a very young patient, though an unusual presentation of Kienböck disease, should be given an adequate trial of immobilization in hopes of allowing revascularization of the lunate and preventing disease progression. Usually it acts as initial management for Stage I disease.

\section{Operative}

A number of options are available for surgical management of Kienböck disease. The two most important pieces of information are the stage of the disease and the presence or absence of ulnar variance.

Operative management can be classified into:

a. Lunate excision with or without replacement.

b. Joint-leveling procedures.

c. Intercarpal fusions.

d. Revascularization.

e. Salvage procedures.

f. Others:

Cancellous bone grafting plus external fixation, Arthroscopic debridement, Wrist denervation, Metaphyseal decompression and Lunate core decompression [10].

\section{Lunate excision with or without replacement}

Simple lunate excision, Excision with soft-tissue (fascial or palmarislongus tendon graft) replacement and Silicone replacement arthroplasty [11].

\section{Joint-leveling procedures}

Radial shortening and ulnar lengthening are the two options for leveling the joint. The goal is to produce a wrist with neutral ulnar variance. Strains at the lunate can be reduced by $70 \%$ with an appropriate radial shortening or ulnar lengthening. Currently, radial shortening with a volar distal radius locking plate is preferred to ulnar lengthening because there is a lower complication rate with the volar-shortening procedure and because the two procedures have shown similarly good outcomes. In patients with neutral or positive ulnar variance, shortening the radius is contraindicated. In this clinical situation, radial wedge osteotomies designed to decrease the radial inclination have been proposed $[12,13]$.

\section{Intercarpal Fusions}

The goal is to reduce lunate strain and to correct and maintain proper scaphoid position in procedures that involve the scaphoid. Of the limited intercarpal fusions reported, the greatest experience has been with scapho trapezio trapezoid (STT) fusion. STT arthrodesis does decrease lunate strain but merely by shifting it to the radioscaphoid joint. STT fusion in a cadaver model was found to provide strain reduction similar to that of joint-leveling procedures but with greater loss of motion.

The use of STT fusion has waned in recent years because of complications and longer-term follow-up that has revealed decreased success rates [14] (Figure 9). Several authors have reported scapho capitate (SC) fusion. Biomechanically, this fusion has been shown to reduce strain at the radiolunate 
joint by about $10 \%$. Some authors prefer this fusion because it requires only one fusion site and is technically easier to perform.

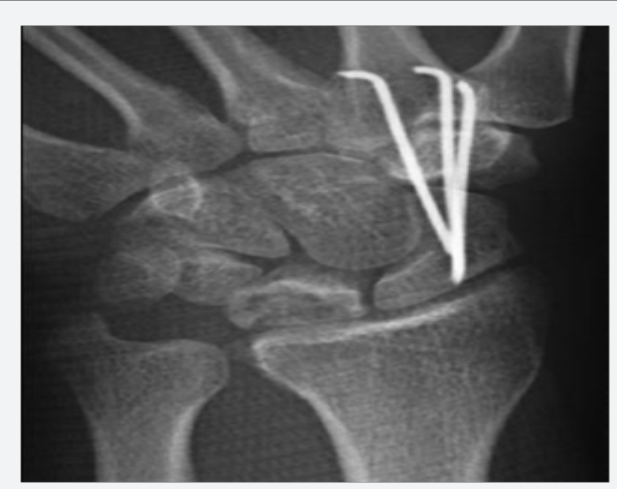

Figure 9: Scaphocapitate (SC) fusion.

Finally, capitohamate fusion has been reported in some studies but a long follow-up is still not available.

At present, intercarpal fusions are more likely to be reserved for patients with neutral or positive ulnar variance in whom a joint-leveling procedure is contraindicated.

\section{Revascularization}

There are several sources for the pedicles, including the distal radius, pisiform, and pronator quadrates [15-18]. Results with the use of pedicled distal radius grafts have shown improved grip strengths and progressive evidence of revascularization on magnetic resonance imaging (MRI) over an 18- to 36-month period [19]. Revascularization techniques may also be combined with other previously mentioned approaches. Revascularization is especially attractive for the young patient with ulnar-neutral or ulnar-positive variance in whom a radial shortening is not an option and for the patient who wishes to avoid an intercarpal fusion and resultant loss of motion.

\section{Salvage Procedures}

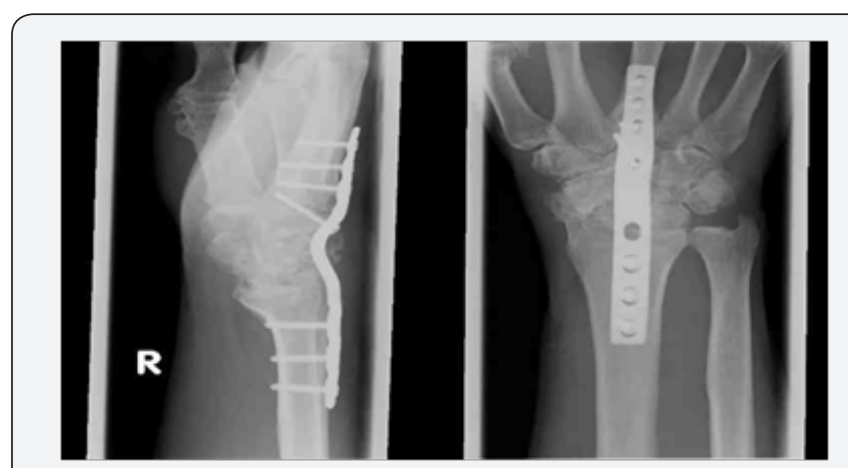

Figure 10: SC arthrodesis has been suggested as an option for wrist salvage in cases of advanced Kienböck disease.

Salvage procedures are reserved for later stages of disease and for failures of other treatments. Proximal row carpectomy (PRC) has been shown to provide relatively good results for Kienböck disease, as well as for other wrist problems [20].
Wrist arthrodesis is the final option for patients with global wrist degeneration. Arthrodesis can be achieved successfully following a failed PRC. SC arthrodesis has been suggested as an option for wrist salvage in cases of advanced Kienböck disease [21] (Figure 10). A reasonable approach to determining the surgical treatment of Kienböck disease based on stage is as follows:

i. Stage 0, I, II, or IIIa with ulnar-negative variance: Radial shortening, revascularization and denervation

ii. Stage 0, I, II, or IIIa with ulnar-neutral or positive variance: Revascularization, capitohamate $(\mathrm{CH})$ fusion with capitate shortening, distal radius wedge osteotomy and denervation.

iii. Stage IIIb: SC fusion, radial shortening and denervation.

iv. Stage IV: PRC, total wrist arthrodesis and denervation.

\section{References}

1. Lutsky K, Beredjiklian PK (2012) Kienböck disease. J Hand Surg Am 37(9): 1942-1952.

2. Bain GI, Yeo CJ, Morse LP (2015) Kienböck Disease: Recent Advances in the Basic Science, Assessment and Treatment. Hand Surg 20(3): 352 365 .

3. De Smet L (1994) Ulnar variance: facts and fiction review article. Acta Orthop Belg 60(1): 1-9.

4. Stahl S, Stahl AS, Meisner C, Rahmanian Schwarz A (2012) A systematic review of the etiopathogenesis of Kienböck's disease and a critical appraisal of its recognition as an occupational disease related to handarm vibration. BMC Musculoskelet Disord 13: 225.

5. Gelberman RH, Salamon PB, Jurist JM (1975) Ulnar variance in Kienbock's disease. J Bone Joint Surg 57(5): 674-676.

6. Gelberman RH, Bauman TD, Menon J (1980) The vascularity of the lunate bone and Kienbock's disease. J Hand Surg 5(3): 272-278.

7. Kulhawik D, Szałaj T, Grabowska M (2014) A vascular necrosis of the lunate bone (Kienböck's disease) secondary to scapholunate ligament tear as a consequence of trauma - a case study. Pol J Radiol 79: 24-26.

8. Bain GI, Begg M (2006) Arthroscopic assessment and classification of Kienbock's disease. Tech Hand Up Extrem Surg 10(1): 8-13.

9. Keith PPA, Nuttall D, Trail I (2004) Long-term outcome of nonsurgically managed Kienböck's disease. J Hand Surg Am 29(1): 63-67.

10. Mehrpour SR, Kamrani RS, Aghamirsalim MR, Sorbi R, Kaya A (2011) Treatment of kienböck disease by lunate core decompression. J Hand Surg Am 36(10): 1675-1677.

11. Ueba Y, Nosaka K, Ikeda N, Seto Y, Nakamura T (1999) An operative procedure for advanced Kienböck's disease. Excision of the lunate and subsequent replacement with a tendon-ball implant. Journal of orthopaedic science 4(3): 207-215.

12. Illarramendi AA, De Carli P (2003) Radius decompression for treatment of Kienbock disease. Tech Hand Up Extrem Surg 7(3): 110-113.

13. Iwasaki N, Minami A, Ishikawa J, Kato H, Minami M (2005) Radial osteotomies for teenage patients with Kienböck disease. Clin Orthop Relat Res 439: 116-122.

14. Lee JS, Park MJ, Kang HJ (2012) Scaphotrapeziotrapezoid arthrodesis and lunate excision for advanced Kienböck disease. J Hand Surg Am 37(11): 2226-2232. 
15. Elhassan BT, Shin AY (2009) Vascularized bone grafting for treatment of Kienböck's disease. J Hand Surg Am 34(1): 146-154.

16. Simmons SP, Tobias B, Lichtman DM (2009) Lunate revascularization with artery implantation and bone grafting. J Hand Surg Am 34(1): 155-160.

17. Mathoulin C, Wahegaonkar AL (2009) Revascularization of the lunate by a volar vascularized bone graft and an osteotomy of the radius in treatment of the Kienböck's disease. Microsurgery 29(5): 373-378.

18. Sheetz KK, Bishop AT, Berger RA (1995) The arterial blood supply of the distal radius and ulna and its potential use in vascularized pedicled bone grafts. J Hand Surg Am 20(6): 902-914.

This work is licensed under Creative Commons Attribution 4.0 License DOI: $10.19080 /$ OROAJ.2017.09.555755
19. Mazur KU, Bishop AT, Berger RA (1997) Vascularized metaphyseal bone grafts from the distal radius in the treatment of Kienbock's disease. Orthopaedic Transactions 21: 244.

20. Kremer T, Sauerbier M, Trankle M, Dragu A, Baumeister S, et al. (2008) Functional results after proximal row carpectomy to salvage a wrist. Scand J Plast Reconstr Surg Hand Surg 42(6): 308-312.

21. Iorio ML, Kennedy CD, Huang JI (2015) Limited intercarpal fusion as a salvage procedure for advanced Kienbock disease. Hand (N Y) 10(3): 472-476.

\section{Your next submission with Juniper Publishers will reach you the below assets}

- Quality Editorial service

- Swift Peer Review

- Reprints availability

- E-prints Service

- Manuscript Podcast for convenient understanding

- Global attainment for your research

- Manuscript accessibility in different formats

( Pdf, E-pub, Full Text, Audio)

- Unceasing customer service

Track the below URL for one-step submission https://juniperpublishers.com/online-submission.php 